\title{
Dr Edward Jenner (1749-1823) of Berkeley, and vaccination against smallpox
}

\author{
Peter M Dunn
}

Edward Jenner was born on 17 May 1749, the eighth child of the Reverend Stephen Jenner, vicar of Berkeley in the county of Gloucestershire. Both his parents died when he was 5 and he was then looked after by his eldest brother. Educated at Wotton-underEdge and Cirencester, at the age of 13 he was apprenticed for seven years to Daniel Ludlow, a surgeon of Sodbury near Bristol. ${ }^{1}$ In 1770 he travelled to London to become a house pupil of John Hunter and a student at St George's hospital. Three years later, resisting the suggestion that he practise in London, Jenner returned to Berkeley to become a country physician: perhaps because he was a keen naturalist.

Besides being both curious and observant, he kept meticulous notes and possessed a happy combination of common sense and scientific logic. Spurred on by John Hunter with whom he had developed a warm friendship and who wrote, 'Why think? Why not try the experiment?', Jenner studied such subjects as the temperature of hibernating hedgehogs, the life history of eels, and the migration of birds. His best known observations were on the cuckoo. This bird was known to lay its eggs in the nests of other birds, particularly the hedgesparrow, and to depend on the foster parents to hatch and feed its chicks. Philosophers since the days of Aristotle had puzzled as to how the foster parent's own chicks came to be ejected from the nest and left to die. Jenner discovered that the cuckoo chick was itself responsible and demonstrated by dissection that the latter had a hollow on its back that enabled it to obtain a good purchase. In one instance he recorded observing two cuckoo hatchlings in one nest. He wrote: 'The contest was very remarkable. The combatants alternately appeared to have the advantage, as each carried the other several times to the top of the nest, and then sunk down again, oppressed by the weight of its burden; till at length, after various efforts, the strongest prevailed'. After his findings had been presented to the Royal Society in 1788, he was elected FRS. ${ }^{2}$

Jenner was a conscientious and successful doctor, a vigorous countryman, and adept at social gatherings. He took pride in his appearance, enjoyed good food, singing and playing the flute and the fiddle, and he wrote poetry about the countryside. In 1788 he married Catherine Kingscote and the following year

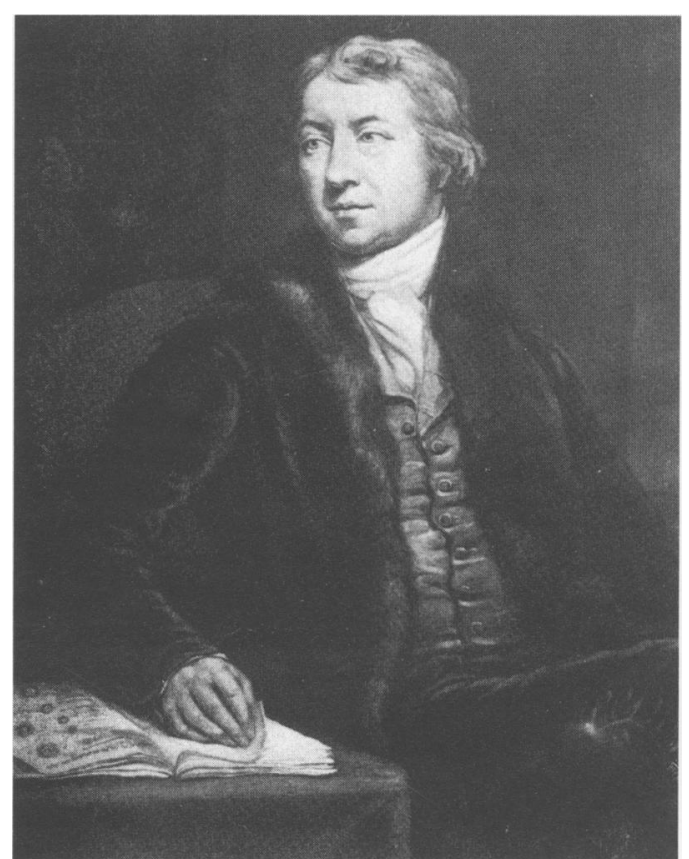

Dr Edward fenner in 1801.

their eldest son, Robert, was born. Hunter became his godfather. A daughter and second son followed. In 1792 Jenner was made $M D$ by the University of St Andrews. This enabled him to practise as a physician in the fashionable spa of Cheltenham. He also helped to establish two local medical societies and presented papers on such matters as mitral stenosis and, importantly, on the association of angina pectoris with coronary artery disease. He was also interested in botany and in 1798 was elected a fellow of the Linnaean Society.

In the 18th century every 10 th person in Europe died of smallpox and the survivors were often terribly scarred. Against this background Jenner, as an apprentice in 1768, first heard a dairy maid claim: 'I can't take the smallpox, for I have already had the cowpox'. During the following years he discussed the matter with Hunter and others, with little response. Indeed, his friends in the west country ConvivioMedical Club threatened him with expulsion if he brought up the subject again. In 1796 Jenner put the theory to test and sent his findings to Sir Joseph Banks, President of the Royal Society. His manuscript was not accepted. Two years later, after further studies, Jenner published his 'Inquiry'3 privately. He began by describing a 
number of people previously infected with cow pox who had then failed to respond to inoculation with smallpox or to catch the disease. Next he described his crucial experiment:

'The more accurately to observe the progress of the infection, I selected a healthy boy (James Phipps), about eight years old, for the purpose of inoculation for the Cox Pox. The matter was taken from a sore on the hand of a dairymaid (Sarah Nelmes), who was infected by her master's cows, and it was inserted, on the 14 th of May, 1796, into the arm of the boy by means of two superficial incisions, barely penetrating the cutis, each about half an inch long. On the seventh day he complained of uneasiness in the axilla, and on the ninth he became a little chilly, lost his appetite, and had a slight headache. During the whole of this day he was perceptibly indisposed, and spent the night with some degree of restlessness, but on the day following he was perfectly well. The appearance of the incisions in their progress to a state of maturation were much the same as when produced in a similar manner by variolous matter. The only difference which I perceived was, in the state of the limpid fluid arising from the action of the virus, which assumed rather a darker hue, and in that of the efflorescence spreading round the incisions, which had more of an erysipelatous look than we commonly perceive when variolous matter has been made use of in the same manner; but the whole died away (leaving on the inoculated parts scabs and subsequent eschars) without giving me or my patient the least trouble.

In order to ascertain whether the boy, after feeling so slight an affection of the system from the Cox-Pox virus, was secure from the contagion of the Small-Pox, he was inoculated on the 1st of July following with variolous matter, immediately taken from a pustule. Several slight punctures and incisions were made on both his arms, and the matter was carefully inserted, but no disease followed. The same appearances were observable on the arms as we commonly see when a patient has had variolous matter applied, after having either the CoxPox or the Small-Pox. Several months afterwards, he was again inoculated with variolous matter, but no sensible effect was produced on the constitution.'

Jenner went on to test the protective effect of vaccination with lymph taken direct from sores on cow's teats, and also of arm to arm vaccination. In his second edition (1800) he wrote:

'Wishing to see the effect of the disease on an infant newly born, my nephew, $\mathrm{Mr}$ Henry Jenner, at my request inserted the vaccine virus into the arm of a child about 20 hours old. His report to me is that the child went through the disease without apparent illness, yet that it was found effectually to resist the action of variolous matter with which it was subsequently inoculated'.

Jenner also noted that cowpox was not transmitted to others sharing the same bed, and that a young woman with several lesions on her hand failed to transmit the disease to the infant she was nursing. Almost in passing he was also the first to describe an allergic reaction; it occurred in a woman, Mary Barge, inoculated with variolous matter in 1791 who had had cowpox 31 years earlier.

The response to Jenner's report was mixed, ranging from disinterest, ridicule, and opposition to gathering enthusiasm, especially abroad. Within a few years many hundreds of thousands of people had been vaccinated around the world and the mortality from smallpox dramatically reduced. Jenner was showered with honours. Parliament awarded him $£ 30000$ and he was given the Freedom of the City of London. He was received by George III, the Tsar, and the King of Prussia, while Napoleon made his famous comment 'Ah! c'est Jenner. Je ne puis pas refuser à Jenner'. In 1813 Oxford University made him a Doctor of Physic. But he remained a modest and loved country practitioner living at the Chantry in Berkeley (now the Jenner Museum). Nearby he built a cottage for James Phipps.

He had a strong faith, and also became a free-mason and a magistrate. In 1815 his wife and eldest son died, probably from tuberculosis, and in 1823 at the age of 74 his own life ended following a stroke. He was buried with his family in Berkeley Church. So passed away one of the greatest benefactors and scientists known to mankind.

\section{Addendum}

Dr Michael Underwood, a London physician and contemporary of Jenner, wrote: ' ... if (vaccination) were universally adopted, the smallpox would in a few years become entirely extinct'. However, vaccination was not made compulsory in England until 1853, and another 126 years were to pass before smallpox was finally eradicated by the WHO vaccination campaign of the 1970 s.

1 Underwood EA, Campbell AMG. Edward fenner: the man and his work. Britsol: John Wright \& Sons Ltd, 1966 Fisher RB, Edward fenner, 1749-1823. London: Andre Deutsch Ltd, 1991

3 Jenner E. An inquiry into the causes and effects of the variolae vaccinae, a disease discovered in some of the western countries of England, particularly Gloucestershire and known by the name of the cow-pox. London: Sampson Low, 1798. 